\section{Adherence and physical activity}

Paraskevi Theofilou, 1,2 Aymara Reyes Saborit3

1Sotiria Hospital for Thoracic Diseases, Athens, Greece; ${ }^{2}$ Centre for Research and Technology, Department of Kinesiology, Health \& Quality of Life Research Group, Trikala, Thessaly, Greece; 3University of Oriente, Department of Psychology, Santiago, Cuba

Exercise training is an integral component in the management of many chronic, lifestyle related diseases. Therapeutic exercise training is an accepted adjunct to medical therapy for two of the four leading causes of death - cardiovascular disease and chronic obstructive pulmonary disease (COPD) - and is considered one of the three cornerstones of treatment for diabetes mellitus. For each of these chronic conditions, the scientific literature clearly demonstrates that exercise is both beneficial and safe when applicable guidelines are followed.1-4 There is also abundant evidence supporting the health benefits of physical activity, including reduced risk for stroke, some cancers, osteoporosis, hypertension, high cholesterol, obesity, osteoarthritis, and all-cause mortality. ${ }^{5}$ Physical activity is also associated with improved psychological health and functional status, ${ }^{3}$ as well as reduced health - care expenditures.

However, data show that a large proportion of adults do not meet physical activity recommendations, and this is a significant public health problem. ${ }^{7}$ These data also likely underestimate the problem of non-adherence, as adults tend to overreport physical activity levels in comparison to objective measures. ${ }^{8,9}$ Research suggests that inadequate adherence to exercise during the intervention period might attenuate the effectiveness of intervention. 10,11 There are many categories of factors related to non-adherence to physical activity, e.g. demographic, health-related and biological, cognitive and psychological, behavioral, program-related and environmental.12,13

Social factors that have been studied as correlates of physical activity include exercise group cohesion, physician influence, and social support. Group cohesion has shown a modest positive correlation with adherence in some studies. ${ }^{14}$ However, physician influence and social supportive environment have been stronger and more consistent correlates of physical activity level and adherence. ${ }^{14}$ Physician advice to exercise has been reported as a correlate of physical activity among the general adult population. ${ }^{15}$ Social support has been significantly associated with physical activity in cross-sectional and prospective studies, both in community samples and within organized exercise groups.16 While both family and friend support for physical activity appear to be influential, 14 the role of the spouse seems to be particularly important. 16

Communication between the patient and the clinician is considered to be central to establishing effective patient rapport.17 Pizzari et al. ${ }^{18}$ have indicated that patients who had a positive relationship with their physiotherapists felt more inclined to attend their clinic appointments and complete their rehabilitation activities during these sessions. Also, adherence to physiotherapy exercise programs was found to be significantly greater when physiotherapists gave patients positive feedback, asked them for feedback about their progress and treatment, regularly monitored their exercise performance and frequently motivated them to do their home exercises. ${ }^{19}$ Conversely, physicians can be responsible for poor levels of adherence if they give patients too much information and if that information is not specific to their needs and disorder. ${ }^{20}$

Evaluation of patients' exercise adherence as a factor in treatment success or failure is thus potentially complex, difficult, and time consuming. ${ }^{13}$ Future efforts to improve adherence may require individually - targeted interventions that consider important patient and disease characteristics.

\section{References}

1. Oga T, Nishimura K, Tsukino M, et al. Analysis of the factors related to mortality in chronic obstructive pulmonary disease: role of exercise capacity and health status. Am J Respir Crit Care Med 2003;167:544-9.

2. Marquis K, Debigare R, Lacasse Y, et al. Mid-thigh cross sectional area is a better predictor of mortality than body mass index in patients with chronic obstructive pulmonary disease. Am J Respir Crit Care Med 2002;166:809-13.

3. Theofilou P. Evaluation of quality of life in Greek patients with heart failure: the role of health cognitions before and after participation in an exercised - based rehabilitation program. J Clin Trials 2012;S2:1-5.

4. Sigal RJ, Kenny GP, Wasserman DH, Castaneda-Sceppa C. Physical activity/exercise and type 2 diabetes. Diabetes Care 2004;27:2518-39.

5. U.S. Department of Health and Human Services. Physical activity fundamental to preventing disease. Washington DC: U.S. Department of Health and Human Services; 2002.

6. Colditz GA. Economic costs of obesity and inactivity. Med Sci Sports Exerc 1999;31: S663-7.

7. Matthews CE, Chen KY, Freedson PS, et al. Amount of time spent in sedentary behaviors in the United States, 2003-2004. Am J Epidemiol 2008;167:875-81.

8. Troiano RP, Berrigan D, Dodd KW, et al. Physical activity in the United States
Correspondence: Theofilou Paraskevi, Centre for Research and Technology, Department of Kinesiology, Health \& Quality of Life Research Group, Trikala, Thessaly, Greece.

E-mail: theofi@otenet.gr

Received for publication: 17 November 2012. Accepted for publication: 6 January 2013.

This work is licensed under a Creative Commons Attribution NonCommercial 3.0 License (CC BYNC 3.0).

(C) Copyright P. Theofilou and A. Reyes Saborit, 2013 Licensee PAGEPress, Italy

Health Psychology Research 2013; 1:e6

doi:10.4081/hpr.2013.e6

measured by accelerometer. Med Sci Sports Exerc 2008;40:181-8.

9. Sallis JF, Swelens BE. Assessment of physical activity by self-report: status, limitations, and future directions. Res Q Exerc Sport 2000;71:S1-14.

10. Kolt GS, McEvoy JF. Adherence to rehabilitation in patients with low back pain. Man Ther 2003;8:110-6.

11. Iversen MD, Fossel AH, Katz JN. Enhancing function in older adults with chronic low back pain: a pilot study of endurance training. Arch Phys Med Rehabil 2003;84:1324-31.

12. Theofilou P. Medication adherence in Greek hemodialysis patients: the contribution of depression and health cognitions. Int J Behav Med 2012. [In print].

13. Theofilou P. Factors affecting level of compliance in chronic patients. J Inter Med 2011;2:1-2.

14. Sallis JF, Owen N. Determinants of physical activity. Physical activity and behavioral medicine. Thousand Oaks, CA: Sage; 1999. pp 110-134.

15. Kreuter MW, Chheda SG, Bull FC. How does physician advice influence patient behavior? Evidence for a priming effect. Arch Fam Med 2000;9:426-33.

16. Wallace JP, Raglin JS, Jastremski CA. Twelve month adherence of adults who joined a fitness program with a spouse vs without a spouse. J Sports Med Phys Fit 1995;35:206-13

17. Purtilo R and Haddad A. Health professional and patient interaction (5th ed). Philadelphia: WB Saunders; 1996.

18. Pizzari T, McBurney H, Taylor NF, Feller JA. Adherence to anterior cruciate ligament rehabilitation: a qualitative analysis. $\mathrm{J}$ Sport Rehabil 2002;11:90-102.

19. Sluijs EM, Kok GJ, van der Zee J. Correlates of exercise compliance and physical therapy. Phys Ther 1993;73:771-86.

20. Sluijs EM. Patient education in physiotherapy: towards a planned approach. Physiotherapy 1991;77:503-8. 